Redes y organizaciones anticomunistas en Paraguay. La XII Conferencia Anual de la Liga Anticomunista Mundial, realizada en Asunción en 1979

Lorena Soler

páginas / año 10 - n 24 Septiembre-Diciembre / ISSN 1851-992X/ pp.55-73/

2018

http://revistapaginas.unr.edu.ar/index.php/RevPaginas

\title{
Redes y organizaciones anticomunistas en Paraguay. La XII Conferencia Anual de la Liga Anticomunista Mundial, realizada en Asunción en 1979
}

\section{Anticommunist networks and organizations in Paraguay. The XII Annual Conference of the World Anti-Communist League, held in Asuncion in 1979}

\author{
Lorena Soler \\ Universidad de Buenos Aires, \\ Consejo Nacional de Investigaciones Científicas y Técnicas, Argentina \\ lorenamarinasoler@gmail.com
}

\begin{abstract}
Resumen
A partir de documentos inéditos y de los periódicos de la época, el artículo se propone reconstruir y estudiar la celebración de la XII Conferencia Anual de la Liga Anticomunista Mundial (LAM; en inglés: World Anti-Communist League, WACL), realizada en Asunción*en abril de 1979 en el marco del régimen stronista (1954-1989).

Asumimos que la celebración del congreso de la LAM, además de haber generado un espacio de socialización de las élites y de haber funcionado como un mecanismo de propaganda política de la propia dictadura, fue un hito cuya observación nos permite analizar la reelaboración de los discursos anticomunistas, en una coyuntura específica dada por el redireccionamiento de las relaciones externas de los países no comunistas desde el gobierno de 1971 cuando la Organización de las Naciones Unidas dejo de reconocer la dictadura de Chang Kai-shek como representante legítimo de la China continental y especialmente bajo la administración de Jimmy Carter (1977-1981), el avance del Sandinismo en Nicaragua, los problemas diplomáticos de Paraguay con EE. UU. por las denuncias de ilícitos, la toma de conocimiento internacional de las violaciones a los DD.HH. y la nueva coyuntura local de crecimiento económico que se abría con la represa de Itaipú. Para ello el texto se organizar en una presentación del problema y una descripción de los cambios de la política de cooperación de Paraguay en el marco de la Guerra Fría y en la red trasnacional de la Liga Anticomunista Mundial. Finalmente se detiene en los cambios de la organización mundial tras la nueva política exterior de EE. UU. y algunas conclusiones del estudio general.
\end{abstract}

Palabras clave

Guerra Fría; Liga Anticomunista Mundial; Paraguay; redes; derechas

\footnotetext{
Abstract

The article seeks on reconstruct and study, from unpublished documents and newspapers of these years, the celebration of the XIIth Annual Conference of the World Anti-Communist League (WACL) in Asunción, during April 1979, within the framework of Stroessner's Esta obra está sujeta a la Licencia Reconocimiento-NoComercial-CompartirIgual 4.0 Internacional de Creative Commons. http://creativecommons.org/licenses/by-nc-sa/4.0/

(cc) BY-NC-SA
} 
Redes y organizaciones anticomunistas en Paraguay. La XII Conferencia
Anual de la Liga Anticomunista Mundial, realizada en Asunción en 1979

regime (1954-1989). We assume that the study of the celebration of this congress, apart from having generated a space for socialization of the elites and having functioned as a mechanism of political propaganda of the dictatorship itself, was a milestone whose observation allows us to analyze the reworking of anti-Communist discourses, at a specific historic moment given by the redirection of the non-communist countries' external relations since the government of 1971, when the United Nations stopped recognizing the dictatorship of Chang Kai-shek as a legitimate representative of mainland China and specially under Jimmy Carter's administration (1977-1981), the advancement of Sandinismo in Nicaragua, the diplomatic problems of Paraguay with the U. S. because of the reporting of illicits, the international aknowledgement of human rights' violations and the new local conjuncture of economic growth allowed by Itaipú's dam.

To this end, the text is organized in a presentation of the problem and a description of Paraguay's cooperation policy changes in the framework of the Cold War and in the transnational network of the Anti-Communist World League. Finally, it stops on the changes of the world organization behind the new foreign policy of the U. S. and some conclusions of the general study.

\section{Keywords}

Cold War; World Anti-Communist League; Paraguay; nets; right-wing parties

\section{Problema y contexto}

La presente propuesta se enmarca en una investigación de más largo aliento que busca trabajar en el campo de los estudios de la Guerra Fría y que coloca a Paraguay dentro de una red global de lucha anticomunista regional y mundial que funcionó en los años 1960-1970. Como parte de ese plan¹, este trabajo estudia la celebración de la XII Conferencia Anual de la Liga Anticomunista Mundial (LAM), realizada en Asunción en abril de 1979, en tanto nos permite observar las ideas y las prácticas anticomunistas puestas en funcionamiento en Paraguay y el lugar que el régimen stronista ocupó en las relaciones internacionales o en las redes de intercambios. Asumimos que la socialización de las élites políticas locales del Partido Colorado efectuada en una red trasnacional anticomunista permite observar cómo los grupos locales percibían la "lucha anticomunista global" y cómo la formación política anticomunista pudo perdurar hasta el presente.

Finalmente, buscamos estudiar las identidades de derechas en una coyuntura histórica específica consignada por la Segunda Guerra Fría, el nuevo entramado geopolítico de Centroamérica, el desconocimiento de la dictadura de Chang Kai-shek como representante legítimo de la China continental por parte de la Organización de las Naciones Unidas, el ascenso de Jimmy Carter al Gobierno de EE. UU. (19771981) los problemas diplomáticos de Paraguay con ese país por las denuncias de ilícitos y la toma de conocimiento internacional de las violaciones a los DD.HH.

\footnotetext{
${ }^{1}$ Tres son las líneas de investigación desarrolladas hasta ahora: Paraguay como parte de una red de socialización política anticomunista con fuerte impacto en los mecanismos de legitimidad del régimen (a través del estudio de La cruzada mundial de la amistad); las revistas de humor político anticomunista como parte de la propaganda ideológica y el ahora estudio de la Liga Anticomunista Mundial.
} 


\section{Lorena Soler}

Este artículo asume el estudio de las derechas que se circunscriben al contexto específico de la Segunda Guerra Fría — o segunda etapa de esta guerra ${ }^{2}$ - y adopta la idea del anticomunismo para entender ciertas actitudes y posturas de las derechas latinoamericanas tomadas en dicho período, en tanto "resulta de interés comprender cómo diferentes ideologías se transforman en proyectos políticos con la intención de influir en la sociedad, y cómo tratan de conservar dicha influencia mediante el uso de recursos políticos para construir imaginarios en diferentes espacios"3. Aun sin ser un elemento discriminador suficiente, sostenemos que el anticomunismo es un fenómeno más grande que la presencia de sujetos que tratan de sacar ventaja de las "creencias" que lo sostienen: "Ciertos agentes políticos adhirieron profundamente a la causa anticomunista, dedicándole tiempo, energía y esfuerzos de organización. Gracias a esos militantes, el anticomunismo se volvió una tradición, un conjunto de representaciones y movimientos políticos reproducidos a lo largo del tiempo, y naturalmente apropiado de diversas maneras según el contexto". 4

En Paraguay, como en otros tantos países, el anticomunismo no nació con la Guerra Fría ni su lucha ha sido idéntica durante los 35 años de "dictadura"5. Acaso el anticomunismo stronista del período de la Segunda Guerra Fría haya sido una de las posibles familias de aquellos agrupamientos de derecha. Abordar el estudio del anticomunismo supone asumir, como lo ha precisado Ernesto Bohoslavsky ${ }^{6}$, al menos dos retos. Por un lado, si bien es claro que entre comunismo y anticomunismo existen procesos de construcción identitaria relacional y que no se trata de un vínculo mecánico, en Paraguay, al igual que otros países, el anticomunismo llevó adelante una práctica preventiva que cobró una dimensión claramente desmesurada frente a las capacidades e intenciones reales de los comunistas. Por otro lado, conviene recordar que el anticomunismo, según el país y la coyuntura histórica, no significó lo mismo para todos los actores; por el contrario, es

\footnotetext{
${ }^{2}$ Según se prefiera la caracterización de María Dolores Béjar. Historia del Siglo XX. Buenos Aires, Siglo XXI, 2011; o Friedrich Katz, "La Guerra Fría en América Latina", en Daniela Spenser (coordinadora), Los espejos de la Guerra Fría: México, América Central y el Caribe. México, Centro de Investigaciones y Estudios Superiores en Antropología Social, 2004, pp.11-31, respectivamente.

3 Raúl Burgos Pinto. "Aproximaciones a la construcción del anticomunismo en la derecha política conservadora en Chile, 1941-1948". Estudos Ibero-Americanos, Vol. XL, № 2, jul.-dez. PUCRS, 2014, pp.258-276.

${ }^{4}$ Rodrigo Patto Sá Motta. "O anticomunismo nas pesquisas de opinião: Brasil, 1955-1964". Nuevo Mundo, Mundo Nuevo [en línea], Colloques. 2014, p.1. Disponible en: $<$ https://nuevomundo.revues.org/68817>. [Consulta: 25/04/2017].

${ }^{5}$ Hay expresiones anticomunistas prodigiosas desde los años 1920. Incluso, en el marco del conflicto con Bolivia, se promulgó la Ley de Defensa Social (Ley № 1292, de 1932), que prescribía con penas de destierro o cárcel a quienes hicieran apología del comunismo o de cualquier otra forma de dictadura, así como para quienes ultrajaran o denigraran los símbolos nacionales.

${ }^{6}$ Ernesto Bohoslavsky. "Organizaciones y prácticas anticomunistas en Argentina y Brasil (19451966)". Estudos Ibero-Americanos, Vol. XLII, Nº 1, enero-abril. PUCRS, 2016, pp.34-52.
} 
Redes y organizaciones anticomunistas en Paraguay. La XII Conferencia
Anual de la Liga Anticomunista Mundial, realizada en Asunción en 1979

observable una diversidad organizativa, ideológica e incluso socioeconómica que permitía la captación de adeptos en capas sociales diversas? ${ }^{7}$.

\section{Los cambios de la política de cooperación en el marco de la Guerra Fría}

El régimen stronista (1954-1989) nació el mismo año en que el mundo se anoticiaba de la creación, por parte de los gobiernos de Seúl, Taipei y Manila, de la Asian Peoples' Anti-Communist Conference (APAC) que buscaba protegerse contra posibles agresiones militares de la China maoísta. Así, fue de principio a fin, un orden político enmarcado en las disputas de la Guerra Fría y se inscribió en los principios rectores de un orden autoritario que pregonaba y ejercía la "democracia sin comunismo". Además, la lucha anticomunista adoptó estatus jurídico al sancionarse la Ley de Defensa de la Democracia (Ley No 294, del 17 de octubre de 1955), que regulaba las penas que se aplicarían a quienes "difundieran la doctrina comunista o cualesquiera otra doctrina o sistema que se propusiera destruir o cambiar por la violencia la organización democrática republicana de la Nación"8.

Como parte de este compromiso internacional y local, el país contó, desde su inicio y hasta mediado de los años 1970, con un apoyo económico inédito de los EE. UU., que fue mucho más allá del plano militar y se expresó en un verdadero programa de modernización autoritaria del país. Todas las áreas del Gobierno, al igual que todos los programas de transformación de la estructura social (desde la tenencia de tierras hasta los planes de infraestructura, pasando por los programas de reforma de los sistemas educativo y de salud), recibieron apoyo técnico y financiero.

Derrotada la experiencia populista de la Argentina y de su aliado guaraní -el por entonces presidente Federico Chaves (1949-1954)—, las relaciones entre EE. UU. y Paraguay bajo el stronismo, entraron en una fase de cooperación sin precedentes, basada en la convergencia de las políticas de seguridad y modernización económica de la Guerra Fría. De esta manera, la "provincia" arrinconada del Río de la Plata se convertía en un lugar geopolítico estratégico.

Como lo señaló claramente un despacho confidencial -emitido el 4 de marzo de 1955 - del embajador norteamericano, Arthur Ageton, al Departamento de Estado norteamericano, "la relativa debilidad e inestabilidad de Paraguay preocupa a EE. UU. y [el país] tiene importancia en cuanto a su localización estratégica en el mismo corazón de Sudamérica. Si Paraguay fuese dominado a complaciente con el comunismo, su localización central le otorgaría gran ventaja estratégica para la infiltración Comunista a los cinco países circundantes (sic)"9.

Ya en un documento del 30 de noviembre de 1955, el mismo embajador se dirigía al entonces ministro de Relaciones Exteriores del Paraguay, Hipólito Sánchez Quell, para informarle que, a pedido del Gobierno paraguayo, el Gobierno de los EE. UU. había aceptado enviar un "experto en asuntos anticomunistas para colaborar con el

\footnotetext{
7 Benedetta Calandra y Marina Franco (editores). La guerra fría cultural en América Latina. Buenos Aires, Biblos, 2012.

${ }^{8}$ Andrew Nickson. La Guerra Fría y el Paraguay. Asunción, El Lector, 2014, p.28

${ }^{9}$ Andrew Nickson. La Guerra Fría y el Paraguay. Asunción, El Lector, 2014, p. 20.
} 


\section{Lorena Soler}

Servicio de Inteligencia Política del Ministerio del Interior, que se dedicaba a combatir las actividades comunistas en el país"10.

Entre los años 1954 y 1961, en pleno proceso de consolidación del régimen stronista, "el monto total de préstamos otorgados por instituciones crediticias norteamericanas, excluyendo gastos militares, llegó a los 53,2 millones de dólares (el 2,74 \% del PBI de Paraguay), aunque también es cierto que el monto solicitado había sido de 75 millones, un volumen, en palabras del embajador Ploser, ‘abultado y nada realista'"11.

A cambio del apoyo económico y político al stronismo, Paraguay acompañó la política exterior propuesta por los EE. UU. —-demandando a la OEA que actuara militarmente contra Cuba- y cedió parte de su soberanía política firmando la cláusula Selden Resolution, que habilitaba la intervención directa de militares en territorio paraguayo en caso de amenaza comunista. Además, apoyó militarmente y en los fueros diplomáticos cada una de las medidas que EE. UU. llevó adelante en la lucha contra el comunismo, que incluyeron el envío de efectivos paraguayos a la República Dominicana para derrocar el Gobierno de Juan Emilio Bosch Gaviño (1963), y el ofrecimiento de colaboración, de la misma manera, en la guerra con Vietnam. La cooperación se afianzó también en el plano cultural, mediante las agencias de promoción de la cultura norteamericana, tales como Las Amigas Norteamericanas del Paraguay, el Centro Cultural Paraguayo Americano y la militancia social de los Cuerpos de Paz, diseminados por todo el territorio guaraní. En síntesis, Paraguay fue visto a largo plazo como un actor nodal para acompañar las políticas norteamericanas en los foros internacionales, especialmente en el sistema interamericano, participando en la formulación de programas políticos y económicos en el continente y permaneciendo como un elemento confiable en el planeamiento de la seguridad hemisférica.

Sin embargo, esta política de cooperación ingresó a mediados de los años 1970 en un franco deterioro, en un contexto dado por el inicio de una nueva etapa de la Guerra Fría, marcada -en principio- por el impacto que tuvo en el campo de la izquierda latinoamericana el triunfo de Fidel Castro - específicamente en su versión comunista-, la derrota de EE. UU. en la Bahía de Cochinos y la alianza de la Unión Soviética con Cuba, que le permitió a los rusos ingresar por primera vez como Estado al continente americano e instalar allí su primera base militar. Luego, sería determinante el cambio que imprimiría el Gobierno de Jimmy Carter en la política exterior de EE. UU. Esta nueva etapa fue altamente convulsionada, debido a las revoluciones que recorrieron el Tercer Mundo, desde América Central hasta Irán e Indochina, pasando por el sur y el este de África. Como indicó Béjar, la "ingobernabilidad de esta nueva parte del mundo", la crisis económica y la presencia soviética en nuevos escenarios afectó las relaciones entre las superpotencias ${ }^{12}$.

\footnotetext{
10 Comisión de Verdad y Justicia, Tomo VII, Asunción, 2008, p. 264.

11 Frank Mora y Jerry Cooney. El Paraguay y los Estados Unidos. Asunción, Intercontinental, 2009, p. 184.

12 María Dolores Béjar. Historia del Siglo..., Op. Cit., p. 213.
} 
Redes y organizaciones anticomunistas en Paraguay. La XII Conferencia
Anual de la Liga Anticomunista Mundial, realizada en Asunción en 1979

En ese contexto, entonces, Paraguay ingresó en un período en el que se deterioraron sus relaciones con EE. UU. y el stronismo adoptó una autonomía relativa en el plano diplomático, en el campo político interno y en el campo de la dependencia económica por su giro hacia Brasil. En el primero influyó el involucramiento directo de Paraguay en el tráfico de drogas - que comprometió la imagen internacional del país y de su aliado internacional- con el llamado "affaire Ricord"13, en el que Andrés Rodríguez (segundo en el comando de las Fuerzas Armadas y cabecilla, en 1989, del golpe contra su consuegro Stroessner) aparecía como uno de los mayores implicados. A esto se sumó el apoyo de la Administración de Jimmy Carter a las denuncias de las violaciones de los derechos humanos, que tuvo repercusiones en el campo político interno. En ese clima, en momentos en que se publicitaban los informes de Amnistía Internacional sobre los casos de tortura y los presos políticos de Paraguay, Stroessner se negó a permitir la misión de la Comisión Internacional de Derechos Humanos de la OEA, y la Embajada de EE. UU. terminó apoyando abiertamente a los opositores del régimen apiñados en el frente Acuerdo Nacional - espacio multipartidario que pugnaba por la apertura democrática-. Sin embargo, la reacción del stronismo fue contraria a cualquier tipo de apertura y reforzó los mecanismos autoritarios, sancionando una enmienda constitucional (1976) que modificaba el Art. 173 de la Constitución Nacional y permitía la reelección indefinida ${ }^{14}$.

Por último, al distanciamiento de las políticas de EE. UU. se suma un factor económico. Desde mediados de 1970, Paraguay experimentó un rápido crecimiento en su economía, fruto de los acuerdos internacionales con Brasil. A la construcción de la represa de Itaipú se sumaron el aumento de la demanda internacional de la soja y el algodón, la expansión de la producción agrícola en la región oriental y la posibilidad de exportar a través de Paranaguá, usando la ruta brasileña. En el total de las inversiones extranjeras, el porcentaje de las norteamericanas comenzó a bajar sensiblemente frente al de las brasileñas ${ }^{15}$.

Todos los factores aludidos se concatenaron y dieron lugar a ciertos grados de autonomía con respecto a la política exterior alentada por EE. UU. Así, lejos de seguir manteniendo las afinidades compartidas, Paraguay, en cierta medida recostado sobre sus relaciones económicas con Brasil, tomaría un nuevo camino en su política

\footnotetext{
13 El francés Auguste Ricord fue un colaboracionista nazi durante la Segunda Guerra Mundial, que en 1967 se estableció en Asunción. En 1970 se incautaron casi cien kilogramos de heroína en el aeropuerto de Miami, recién llegadas de Paraguay (uno de los pilotos detenidos mantenía una relación laboral directa con el general Andrés Rodríguez, yerno de Alfredo Stroessner). Al principio, Stroessner rechazó el pedido de extradición norteamericano de Ricord y EE.UU. amenazó con cortar todas las relaciones económicas. Finalmente, el Gobierno paraguayo cedió y Ricord fue condenado a 20 años de prisión. El caso obtuvo una repercusión internacional altísima al recibir cobertura periodística del influyente columnista del Washington Post, Jack Anderson, y reproducida por la revista Selecciones, de Reader's Digest.

14 Los partidos políticos apelan abiertamente a un "posicionamiento abstencionista" frente a los siguientes comicios $(1978,1983,1988)$, que se realizarían sin mayor trascendencia.

15 Puede ampliarse este punto en varios de los capítulos reunidos en Dionisio Borda y Fernando Masi (editores). Estado y economía en Paraguay. 1870-2010. Asunción, CADEP, 2010.
} 


\section{Lorena Soler}

externa e interna, al punto de llegar Stroessner a denunciar al Gobierno estadounidense por intervencionista (claro está que las presiones de EE. UU. contra el régimen, durante esos años del "boom de Itaipú", suponían escasos riesgos de desestabilización política para el Paraguay). En síntesis, el régimen de Stroessner se convirtió en una "víctima de la tregua de la Guerra Fría y de la preocupación norteamericana por los derechos humanos, la democracia y el tráfico de drogas" 16 . Si durante las primeras décadas de la dictadura de Stroessner las relaciones bilaterales pueden ser calificadas como cordiales y confiables, desde mediados de los años 1970 se caracterizaron por el conflicto. La ayuda económica cesó, la asistencia militar se redujo y las relaciones comerciales se deterioraron.

En este marco debe interpretarse el hecho de que Asunción haya sido elegida como sede para la realización, primero, del Tercer Congreso de la Confederación Anticomunista Latinoamericana (CAL, del 28 al 30 de marzo de 1977) ${ }^{17}$ y, luego, de la XII Conferencia Internacional de la Liga Anticomunista Mundial (LAM, del 23 al 27 de abril de 1979), encuentros en los que varios funcionarios "expresaron su disgusto $\mathrm{y}$ profundo resentimiento por las intervenciones ilegales del embajador norteamericano en los asuntos internos del Paraguay". Ya en el Congreso de la CAL, el subsecretario paraguayo Antonio Campos Alum ${ }^{18}$ propuso dar "amplia difusión de la maniobra de Carter contra los gobiernos nacionalistas de nuestro continente", para establecer una alianza "ante la cual el Cartercomunismo sería impotente"19.

Finalmente, los cambios geopolíticos mundiales hicieron que la LAM se convirtiera en el refugio de los Gobiernos y organizaciones afectados por la política exterior de Jimmy Carter. Según Fabricio Antonio Fonseca Fernández ${ }^{20}$, en enero de 1979, el Gobierno de EE. UU. decidió poner fin unilateralmente al Tratado de Defensa Mutua con la República de China (Taiwán), para así formalizar el establecimiento de relaciones diplomáticas con la República Popular de China. El cambio de reconocimiento diplomático hacia Beijing por parte de Washington mandó una

\footnotetext{
16 Ricardo Yegros Scavone y Liliana Brezzo. Historia de las relaciones internacionales del Paraguay. Asunción, El Lector, 2010, p.152.

17 El primer Congreso Constitutivo de la CAL se realizó el 28 de agosto de 1972 en Guadalajara (México). La organización llevó a cabo un congreso secreto en Asunción entre el 28 de mayo y el 1 de junio de 1973 y un II Congreso en Río de Janeiro entre el 23 y el 27 de enero de 1974. La Secretaría General fue ejercida por el mexicano Dr. Rafael Rodríguez. Ver: Julieta Rostica. "La confederación anticomunista latinoamericana y las Fuerzas Armadas. Guatemala y los años setenta". En Segundo Coloquio Pensar las derechas en América Latina en el siglo XX, Universidad Nacional de General Sarmiento, 13 al 15 de julio de 2016. Disponible en <https://nuevomundo.revues.org/>.

${ }^{18}$ Fue un personaje siniestro del régimen stronista que dirigía el centro de inteligencia y tortura bajo el rótulo de la Dirección Nacional de Asuntos Técnicos. Bajo la etiqueta de "lucha anticomunista", estableció una red extensiva de informantes de la Policía Según los datos aportados por la Comisión de Verdad y Justicia y Andrew Nickson, Campos Alum sirvió como enlace clave del régimen con la CIA y el FBI y recibió entrenamiento en EEUU.

${ }^{19}$ Los entrecomillados responden a documentos organizativos de la LAN. Ministerio de Relaciones Exteriores, Asunción-

${ }^{20}$ Fabricio Antonio Fonseca Fernández. "En búsqueda de la visibilidad: la cooperación internacional de Taiwán”, en Francisco Javier Haro Navejas y Kenia María Ramírez Meda, (coordinadores), Cooperación internacional para el desarrollo y su futuro incierto: teoría, actores, cambios y límites, Universidad Autónoma de Baja California, 2017, pp. 225-309.
} 
Redes y organizaciones anticomunistas en Paraguay. La XII Conferencia
Anual de la Liga Anticomunista Mundial, realizada en Asunción en 1979

señal clara al resto del mundo y ocasionó que un mayor número de países rompiera relaciones con Taipéi y buscara un acercamiento con las autoridades continentales.

\section{Paraguay en la red trasnacional de la Liga Anticomunista Mundial}

La LAM fue una organización internacional de extrema derecha y debe ser entendida como parte de una "red trasnacional ideológica empeñada en derrotar lo que era percibido como un enemigo internacional multifacético que amenazaba a la sociedad occidental"21.

La LAM, que significó "la realización máxima del movimiento anticomunista continental"22, se fundó en Taipéi en 1967 por iniciativa del entonces dictador Chiang Kai-shek - presidente honorario vitalicio-, y contaba con financiación directa del Gobierno de Taiwán ${ }^{23}$. Surgió de la fusión de dos organizaciones anticomunistas previas: el Bloque Antibolchevique de las Naciones (ABN) y de la Liga Anticomunista de los Pueblos de Asia (APAC). Su financiamiento estaba asegurado por la Iglesia de la Unificación, liderada por Myung Monn, y creció especialmente en los primeros años de la década de 1970, cuando Richard Nixon y Henry Kissinger ocupaban la Casa Blanca. Como ha indicado Ernesto Bohoslavsky ${ }^{24}$, después de 1971 la Organización de las Naciones Unidas decidió quitarle a la dictadura de Chang Kai-shek el reconocimiento legítimo como representante de la China continental. Esto sumado al acercamiento de la administración Nixon a Pekín, seguido por varios gobiernos latinoamericanos, redujo la zona de influencia de Taiwán.

En dicho período, Taipei y Seúl se vieron obligados a buscar, apoyar y retener nuevos aliados más allá del gobierno de los EE. UU., transcendiendo al territorio asiático y proyectándose a los seis continentes y abriendo capítulos en Japón, Europa, Gran Bretaña, Australia, EE. UU. y América Latina. En efecto, "[s]i las primeras 5 conferencias se ubicaron en ciudades asiáticas, las 3 siguientes se realizaron en las Américas"25.

\footnotetext{
${ }^{21}$ Ariel Armony. "Transnacionalización de la guerra sucia: Argentina en Centroamérica”, en Daniela Spenser (coordinadora), Los espejos de la..., Op. Cit., p. 320.

22 Luis Hernán Ávila. "Las guerrillas blancas: anticomunismo transnacional e imaginarios de derechas en Argentina y México, 1954-1972". Quinto Sol, Vol. XIX, № 1, enero-abril. 2015, pp. 1-26 (p. 19).

23 Desde 1957, Paraguay vota por el reconocimiento de Taiwán como miembro de las Naciones Unidas. Las relaciones tan cercanas con ese país continuarían después de la caída de Stroessner, y en 2014, Paraguay sería el único país de América del Sur que seguiría reconociendo a la República de China (Taiwán) y no a la República Popular China. Desde la década de 1970, Taiwán desarrolla una agresiva política de inversiones económicas en Paraguay. Ver: $<$ https://noticias.nat.gov.tw/index.php>.

${ }^{24}$ Ernesto Bohoslavsky. "Treinta flores de ciruelo y treinta flores de mburucuyá. Los vínculos de la World Anticommunist League con América Latina durante la guerra fría", en Samantha Quadrat y Ana Mauad (eds.) Memória e História: questões para o tempo presente, Letra e Voz, Río de Janeiro, en prensa.

25 Ídem.
} 


\section{Lorena Soler}

En el Cono Sur estableció filiales como la Confederación Anticomunista Latinoamericana (CAL, 1972), que contó con representantes de México, Paraguay, Argentina, Brasil, Uruguay, Chile, Colombia, Bolivia, Guatemala, El Salvador y Cuba (exiliados). Según Thierry Meyssan y María Rosa Borrás ${ }^{26}$, Hugo Banzer Suárez presidió la rama latinoamericana de la Liga Anticomunista y fue quien organizó el plan sistemático de persecución a los opositores. Estas organizaciones desarrollaron una extensa labor durante los Planes Phoenix ${ }^{27}$ y el Operativo Cóndor. En un cable ministerial emitido el 11 de abril de 1977 por el presidente Honorario de la LAM, Ku Cheng-kang, al Ministro de Relaciones exteriores de Paraguay Alberto Nogués, se le agradece al Gobierno paraguayo por el otorgamiento de la condecoración de la Orden Nacional del Mérito y por la "gratísima e inolvidable experiencia de observar de cerca el alto grado de adelanto y prosperidad alcanzado en vuestro país, así como por poder cambiar impresiones con Vuestra Excelencia sobre la situación anticomunista local".

La LAM, además de estar vinculada con los estamentos gubernamentales, incorporó a su causa a organizaciones de la sociedad civil. Según el Informe de la Comisión de Verdad y Justicia ${ }^{28}$, la Liga, en Paraguay, articulaba con organizaciones intermedias y corporaciones, organizadas en torno a la Comisión de Entidades Cívicas Anticomunistas bajo la coordinación de Antonio Campos Alum. Allí se agrupaba a la Asociación de Profesionales Universitarios del Paraguay, la Asociación de Empresarios Paraguayos y la Federación Universitaria del Paraguay (FUP). Además, contaba con militares, jefes de inteligencia y policías, con los censores ideológicos del régimen (jefes de prensa, escritores, intelectuales), con militantes de extrema derecha de la Iglesia católica y con sindicalistas.

La organización del congreso de la LAM realizado en Asunción se inició con un año de anticipación y ocurrió meses antes de que en Nicaragua se desarrollara el XII Congreso de la Liga Mundial Juvenil Anticomunista. El comité ejecutivo, reunido en Honolulu (Hawaii) del 27 al 30 de noviembre de 1978, designó a Paraguay como sede (en caso de no aceptar se convocaría a Argentina o a Irán). El comité prometió que participarían ciento nueve organizaciones de ochenta y cinco países y "se estimó que llegarían a Asunción de trescientos a trescientos cincuenta delegados e invitados extranjeros, a los que sumarían cien paraguayos ... y se constituiría en el congreso más concurrido de los celebrados hasta ahora"29. Un apartado fue dedicado a los invitados especiales, entre lo que se encontraban tres congresistas de EE. UU., "conocidos en su clara posición anticomunista, seis parlamentarios europeos de Alemania, Suecia, Bélgica, Francia Italia y España, más tres destacados dirigentes de África y tres de América Latina". El congreso eligió como presidente a

\footnotetext{
26 Thierry Meyssan y María Rosa Borrás. "La liga anticomunista mundial, una internacional del crimen". Mientras Tanto, № 93. Icaria Editorial, 2004, pp.133-139.

${ }^{27}$ Fue un programa diseñado por la Agencia Central de Inteligencia (CIA) con el fin de perseguir a quienes participaban apoyaba a la insurgencia del Frente Nacional de Liberación de Vietnam.

28 Comisión de Verdad y Justicia, Tomo VII, Asunción, 2008, p. 28.

${ }^{29}$ Memorando organizativo, Ministerio de Relaciones Exteriores,1979.
} 
Redes y organizaciones anticomunistas en Paraguay. La XII Conferencia
Anual de la Liga Anticomunista Mundial, realizada en Asunción en 1979

Juan Manuel Frutos, director del Instituto de Bienestar Rural (IBR) desde su fundación (1963), organismo responsable de conceder tierras públicas a dirigentes del partido de Gobierno y de las Fuerzas Armadas.

El evento contó con cobertura de la prensa local y fue vivido como un relanzamiento político de la dictadura stronista. Ya en el memorándum organizativo, enviado a Stroessner, el presidente del capítulo paraguayo, Juan Manuel Frutos, aconsejaba que Asunción se erigiera como sede para la XII Conferencia bajo el lema "Unidos venceremos. La libertad no se negocia", y argumentaba: "Dado que en 1979 no se realizarán elecciones nacionales, ni municipales, ni convención partidaria, entendemos que dicho Congreso constituirá uno de los principales acontecimientos políticos del año".

Los diarios de la época fueron informando de las reuniones preparatorias que involucraban directamente al Partido Colorado. En la dirección de relanzamiento de un régimen que atravesaba una crisis política, fueron convocados los presidentes de las veinticinco secciones capitalinas, como así también los presidentes de los organismos auxiliares de la Junta de Gobierno, "a fin de informarse sobre la realización del congreso anticomunista en Asunción" y contar con ellos para el acto inaugural ${ }^{30}$. El Gobierno, además, financió publicidad oficial en todos los periódicos nacionales desde el 18 de abril hasta el día en que finalizó el congreso. Eran placas que ocupaban medio tabloide y apelaban a frases que daban cuenta de la necesidad moral de combatir el comunismo. "El Paraguay es y seguirá siendo un bastión inexpugnable frente a las acechanzas del imperialismo totalitario y ateo del comunismo apátrida en Defensa de los sagrados valores de Dios, Patria, Familia y Libertad", o también: "EL COMUNISMO ES UNO SOLO: siempre ateo, apátrida, sanguinario. Un imperativo: la destrucción".

Un día antes de que comenzara el congreso se realizó una conferencia de prensa en el Hotel Guaraní, y la inauguración oficial tuvo lugar en el Cine Victoria, donde hablaron Stroessner, Roger Pearson, Ku Cheng-kang y Juan Manuel Frutos. Este último, nuevo presidente de la LAM, se preguntó: “¿Se tiene alguna noticia de que alguna vez un organismo internacional haya condenado a un Gobierno comunista por la violación sistemática de los más elementales derechos humanos?". Antes había declarado: "Nuestro líder presidente [Stroessner] no solamente es considerado como un líder a nivel nacional, sino que es la bandera más firme como líder mundial anticomunista, conforme va a poder comprobarse ante la presencia de los delegados de 89 países que asisten a nuestro país"31.

La ceremonia se inició con una dotación de cadetes del colegio militar "Mariscal Francisco Solano López", que fueron los responsables de dar ingreso a la bandera de la LAM, y con la orquesta sinfónica de la ciudad de Asunción, que entonó el himno; en el mismo acto, Juan Manuel Frutos asumió formalmente la presidencia, ocupada hasta allí por Carlos Barbieri Filho, presidente del capítulo de Brasil. En ese contexto

\footnotetext{
30 Hoy, Asunción, 19/04/1979, p. 2.

31 Hoy, Asunción, 23/04/1979, p. 9.
} 


\section{Lorena Soler}

se leyó la carta que el presidente Anastasio Somoza, de Nicaragua, enviara a Stroessner "para expresar en nombre del pueblo de Nicaragua, homenaje, solidaridad democrática, simpatía personal y reconocimiento a vuestra indeclinable posición anticomunista" ${ }^{32}$. También se sumaron los mensajes del presidente de China, Chiang Ching-kuo; el presidente de la junta militar de Honduras, general Policarpo Paz García, y el vicepresidente de la República de Brasil. Del presidente del Partido Movimiento de Liberación Nacional, de Guatemala, Stroessner recibió la condecoración "Orden de Liberación Nacional", creada por el ex presidente guatemalteco Carlos Castillo Armas. La ceremonia inaugural continuó en la Plaza Independencia ${ }^{33}$, donde se realizó un acto público en el que se descubrió una placa recordatoria que todavía hoy se conserva. De ese acto público participaron el cura chileno Florencio Infante y el senador nacional Ezequiel González Alsina y miembros del Partido Colorado, especialmente los jóvenes.

Todos los diarios de la época titularon que participaban del congreso cuatrocientos delegados de ochenta y siete países. Entre las figuras destacadas, además de los ya nombrados, se encontraban Vaal Netu Hendrik, jefe del Departamento de Relaciones Exteriores del Frente Nacional de Liberación de Angola; Hugo Medina, jefe del Estado Mayor del Ejército de Uruguay; Blas Piñar, diputado español ${ }^{34}$, franquista, militante católico y fundador de la fuerza de derecha Fuerza Nueva; ministros de Guatemala y Nicaragua; diputados de Venezuela; los embajadores de Australia y de Marruecos; Ku Cheng-kung, vicepresidente de la Asamblea de Asuntos Constitucionales de la Asamblea Nacional China Nacionalista, y Sheik Ahmed Salah Jancon, de Arabia Saudita. Era además la primera vez que participan miembros del capítulo de la EUROWALC de la LAM.

Como durante el Gobierno de Jimmy Carter la organización pasaba por un período de desfinanciamiento, entre los aspectos organizativos también se solicitaba a Stroessner el monto de 100.000 dólares, que se sumaría a los 202.400 dólares aportados por los países miembros que integraban el comité ejecutivo. Parte del gasto local se financió con fondos de la Unión Industrial Paraguaya y del empresariado local ${ }^{35}$. Dado que el financiamiento fue un punto sensible de la organización, denunciado por la oposición, en varias ocasiones, los organizadores paraguayos debieron aclarar en la prensa que el congreso "se financiaba totalmente con aportes de empresarios locales y de los capítulos que integraban la WACL"36. La prensa local realizó una amplia cobertura del evento internacional, siguió día por día el calendario oficial -típicamente compuesto de eventos protocolares y diplomáticos- y cubrió las declaraciones de las figuras más resonantes.

\footnotetext{
32 Hoy, Asunción, 24/04/1979, p.12.

33 Ídem, tapa.

${ }^{34}$ Encargado de inaugurar el acto público organizado por la "Juventud Estudiosa Colorada" con motivo de la conferencia de la LAM.

35 Entre otros empresarios contribuyeron Alberto Antebi, Nicolás Bo, Blas Riquelme, y Aldo Zuccolillo (éste último, dueño del diario $A B C$ Color).

${ }^{36}$ ABC Color, Asunción, 22/04/1979, p. 7.
} 
Redes y organizaciones anticomunistas en Paraguay. La XII Conferencia
Anual de la Liga Anticomunista Mundial, realizada en Asunción en 1979

Específicamente, el diario $A B C$ Color $^{37}$ fue quien más páginas dedicó y siempre ocupó buena parte de la tapa para su difusión, lo cual no le impidió incluir notas, voces y análisis críticos sobre el congreso y dar espacio a las denuncias por la violación de los DD.HH. del régimen stronista.

En efecto, ningún diario fue monocorde a la hora de cubrir la realización del evento y fueron varias las voces disonantes que aparecieron allí. El 25 de abril, a poco de transcurrir el evento, el diario $A B C$ Color cubría un panel realizado en el Centro Cultural Paraguayo titulado "Democracia: hacia una definición". Participaron intelectuales y políticos de la época vinculados a partidos políticos opositores al régimen stronista: Jerónimo Irala Burgos, el senador nacional Bacón Duarte Prado, José María Rivarola Matto, José Antonio Bilbao Zubizarreta. El evento, organizado por la embajada de EE.UU., contó con la moderación de Thomas Charouhas, de la Agencia de Comunicaciones Internacionales de dicha embajada, y con la presencia del embajador de ese país, Robert White. Se sumaron el líder del Partido Liberal y quien luego sería el principal referente de la transición a la democracia en Paraguay, Domingo Laíno. El evento tuvo una amplísima cobertura en el diario, que reprodujo tanto la discusión suscitada por la adenda constitucional que convertía a Stroessner en un "presidente vitalicio", como la intervención de los participantes cuando calificaban a Somoza de criminal "que ha cometido delitos contra la propia Humanidad". Asimismo, los panelistas respaldaron la política de Carter: "Lo que le deben los presos políticos de todo el mundo (de la Habana, de Asunción) es haber devuelto la confianza en un valor supremo, los derechos humanos"38.

Días después, y aprovechando la prensa internacional que seguía al congreso, Domingo Laíno denunciaría el totalitarismo del régimen stronista y la persecución a los propios integrantes del Partido Colorado que el 30 de mayo de 1979 cumplirían 20 años en el exilio.

Sin duda, el momento por el cual atravesaba el régimen de Anastasio Somoza - a pocos meses del triunfo de la revolución sandinista - también repercutía en la forma en la que se podía defender al anticomunismo. En una editorial del mismo diario, en la que se sostenía que la libertad está asociada a la democracia representativa, se afirmaba que "el reciente Congreso de la Liga de la Juventud Anticomunista realizado en Nicaragua se oponía a la democracia mundial por utilizar procedimientos distanciados de los de la democracia representativa, desprestigiando la lucha anticomunista" 39.

\footnotetext{
37 Las razones de la mayor cobertura se desprenden de varias causas. En principio porque era un diario nuevo (1967) que venía a innovar en las formas de edición y producción periodística. Podemos decir que con él nace la era del periodismo profesional y el nuevo concepto de prensa independiente y empresarial. Se adopta el tabloide como tamaño, se incorporan la impresión en el sistema off-set color y el uso masivo de fotografías en colores. Si bien el dueño de este diario había aportado recursos económicos al congreso de la LAM, no por eso dejó de presentar voces críticas. Incluso en 1984 fue censurado por una orden del Ministerio del Interior.

${ }^{38}$ ABC Color, Asunción, 25/04/1979, p. 13.

${ }^{39}$ ABC Color, Asunción, 25/04/1979, p. 14.
} 


\section{Lorena Soler}

En la misma dirección, en una nota realizada al Dr. Miguel Martínez Yaryes presidente del Partido Liberal Auténtico y uno de los artífices del Acuerdo Nacional - bajo el título "Practican los mismos sistemas represivos", se emprendía una aguda y abierta crítica al stronismo y al propio congreso de la LAM. En la misma página, en un recuadro menor, aparecía la invitación a la presentación del libro Paraguay: represión, estafa y anticomunismo, del Dr. Domingo Laíno. Antes, el 24 de abril, había ocupado un lugar destacadísimo una larga entrevista realizada a Carmen Lara Castro, presidenta de la Comisión Nacional de los Derechos Humanos, quien indicaba que "Donde hay paz, pero con justicia, donde hay igualdad, donde hay auténtica democracia, no se puede temer al comunismo" 40 .

En este contexto, Paraguay propuso como conclusión de la Conferencia de la LAM, en lo referente al capítulo especial sobre los medios de comunicación, "convocar al empresariado a abstenerse de financiar publicaciones procomunistas 0 paracomunistas que se ocupen de desfigurar la realidad de los países anticomunistas para promover el descrédito internacional ... e insten a las agencias internacionales de noticias a informar sobre la violación de los derechos humanos que ocurran en todos los países del mundo" 41.

\section{La LAM y su giro geopolítico tras la nueva política exterior de EE.UU.}

Sucintamente puede decirse que dos fueron las áreas nodales que ocuparon la atención de la LAM en el congreso celebrado en Asunción. Por un lado, una agenda geopolítica centrada en la política exterior desplegada por Carter en América Latina -especialmente en Centroamérica-, el reconocimiento de EE.UU. de la China Comunista y la nueva amenaza roja que podía implicar el ahora eurocomunismo. Por otro lado, reaparecía una fuerte discusión por el papel de la ONU en relación con la violación de los DD.HH., tanto por parte de los regímenes totalitarios comunistas como de los propios países reunidos en la LAM. Y a estas dos áreas se sumó el rol de la Iglesia, que tras las conferencias de Obispos de Medellín y Puebla, parecía inclinar la balanza a favor del comunismo de tal forma que la LAM decidiría solicitar al Papa que aclarara el significado real del dogma católico, en tanto "muchos lo interpretaban según su conveniencia"42.

En lo que respecta al nuevo mapa geopolítico, el secretario general de la Conferencia Anticomunista Latinoamericana, el mexicano Rafael Rodríguez, describió un panorama de América Latina en el cual percibía el resurgimiento comunista ante la "política distractora" del nuevo Gobierno norteamericano. En su intervención, la única de todo el congreso a la cual no pudo acceder la prensa, y que luego fue reproducida en fragmentos por los periódicos de la época, denunció al presidente norteamericano de retirar el apoyo militar y económico a los Gobiernos anticomunistas y de fortalecer los regímenes marxistas, poniendo en pie de igualdad

\footnotetext{
${ }^{40}$ ABC Color, Asunción, 24/04/1979, p. 14.

${ }^{41}$ ABC Color, Asunción, 25/04/1979, p. 15.

${ }^{42}$ ABC Color, Asunción, 26/04/1979, p. 13.
} 
Redes y organizaciones anticomunistas en Paraguay. La XII Conferencia
Anual de la Liga Anticomunista Mundial, realizada en Asunción en 1979

a Moscú, La Habana y Washington, quienes "mantienen a nuestras naciones bajo el juego cruzado de la guerrilla". En lo que sería una preocupación constante por la región de Centroamérica, declaró que Carter financiaba dictaduras como la de Castro $^{43}$ y la de Omar Torrijos. En relación con esta última, recordemos que Carter firmó, en la sede de la OEA en Washington, tratados que establecieron la restitución a la soberanía panameña del Canal Interoceánico y su zona circundante, tras siete décadas de control civil y militar ${ }^{44}$. A raíz de esto, el 26 de abril en un comunicado de la LAM, se solicitaba que los países anticomunistas rompieran relaciones con Panamá.

Por su parte, el representante de Nicaragua en el congreso advertía que, víctima de la invasión militar y el bloqueo económico, "su país enfrentaba la más cruel y criminal embestida del comunismo internacional ${ }^{45}$ "46. El comunicado de la LAM también advertía sobre el retorno de los comunistas a Bolivia con Paz Estenssoro y Hernán Siles Suazo, "hombres de la Segunda Internacional y manchados con la sangre de miles de víctimas", e indicaba que el ejército de Perú tenía infiltrados comunistas en sus filas y que ese país, junto con Panamá, favorecían nuevas constituciones con "ribetes comunistas" 47.

Otro eje central fue la nueva política hacia la China comunista y el nuevo mapa geopolítico asiático. En el documento final se advertía que "los intentos de unirse a la China roja solo han afectado al mundo libre, en vez de debilitar a las fuerzas rojas ...; todo intento de enfrentar un grupo rojo en contra de otro, solo puede conducir al desastre" 48 .

Por último, se pidió condenar el abandono chino y proclamar la independencia de Taiwán. A su turno, Ku Cheng-kang manifestó que era necesaria la industrialización del continente latinoamericano y el establecimiento de un sistema de seguridad regional para contrarrestar la expansión comunista que se estaba dando en América Latina. Criticó el reconocimiento de Carter de Peiping (Beijing), con lo que la seguridad de los países libres del sudeste asiático quedaba amenazada. A su entender, el poderío naval soviético se había extendido al golfo Pérsico, el océano Índico, el Mar de Japón y el Mar de China.

El eurocomunismo tal vez haya sido el punto de mayor debate, lo que quedó plasmado en el documento final. Se denunciaban "las nuevas tácticas como parte del plan comunista de dominación mundial" y se asumía que "irían a buscar el poder por

\footnotetext{
43 En 1977, Carter acordó establecer relaciones de tipo consular con Cuba siendo el resultado de ello la apertura en las capitales respectivas de unas "secciones de intereses". Washington, además, restauró los vuelos chárteres desde Florida y eliminó algunos capítulos del bloqueo económico a la isla, vigente desde la crisis de los misiles de 1962.

44 Los Tratados, rechazados por el Partido Republicano, fueron ratificados por el Congreso.

45 Tres meses después de finalizado el congreso, el 16 de julio de 1979, luego del triunfo de la Revolución Sandinista, Anastasio Somoza renunciaba a la Presidencia y se exiliaba en Asunción, donde sería asesinado en septiembre de 1980.

46 ABC Color, Asunción, 25/04/1979, p. 15.

47 ABC Color, Asunción, 24/04/1979, p. 14.

48 Ibídem.
} 


\section{Lorena Soler}

medio de la subversión en la democracia parlamentaria". La polémica por el destino de Europa impidió que se pudiera designar una nueva sede del congreso. En el cierre del encuentro, luego de una "acalorada reunión", no hubo acuerdo sobre la próxima sede y se decidió que fuera en ese continente "una vez que se produjera la unificación de los dos bandos existentes"49.

La mirada atenta que EE.UU. venía depositando en el régimen stronista - a causa de la violación a los derechos humanos y el tráfico de drogas- hizo que Paraguay dedicara muchos esfuerzos a proyectar otra imagen internacional que precisamente lo alejara de los escándalos que atravesaba. Tanto es así que Paraguay hizo una intervención, en el marco de la LAM, para solicitar a la ONU que "se ampliara la Declaración de los Derechos Humanos a fin de que se contemplaran los derechos de las naciones que son agredidas por el imperialismo soviético, chino y cubano, que tratan de imponer el comunismo" 50 . El comunicado de la LAM también esgrimía que Carter alentaba a Gobiernos y partidos socialistas, socialdemócratas y demócratas cristianos para enfrentarlos en la coalición anticomunista dentro de la ONU ${ }^{51}$, la OEA y el Consejo Interamericano de Seguridad.

También se solicitó a los Gobiernos que recibieran a los inmigrantes refugiados de los regímenes comunistas y que condenaran "la explotación obrera en Cuba y a todos los regímenes comunistas haciendo un llamado a la conciencia del mundo contra esta práctica, solidarizándose con los obreros explotados y engañados". En el documento final se volvía sobre la política de DD.HH. y se consideraba que a los países comunistas no se los sancionaba ni acusaba por su violación: "Urgimos medidas punitorias contra el régimen de Castro ... y apoyamos a los cubanos oprimidos en cualquier intento de derrocar a esta tiranía roja". Se instaba, también, a EE.UU., Canadá y a todos los países no comunistas de Asia, el Pacífico y la Australasia a revertir sus políticas de concesiones y de no alineación.

Por último, habló Frutos en su flamante puesto como director de la LAM. Recordó que el comunismo ya no creía en la "panacea milagrosa del marxismo-leninismo como ideología", sino en el poder de la "fuerza bruta". Asumió como compromiso perfeccionar la democracia con sentido económico y social, es decir, acelerar el desarrollo nacional para erradicar la miseria, a fin de que "los problemas sociales nunca tuvieran carácter explosivo"52. En síntesis y como podía observarse, al tiempo que se proponía un plan geopolítico de máximo control, se bregaba por la economía

\footnotetext{
49 Los lugares propuestos de Europa fueron Austria (Salzburgo) y Portugal. También hubo una tercera postura que fue Alemania (Múnich). Dicho punto demoró el cierre. Una de las recomendaciones finales fue encomendar al comité ejecutivo de la LAM la conformación de una comisión ad hoc de estudio para lograr la unidad de los dos grupos europeos, a fin de que se pudiera integrar un bloque único de lucha contra el enemigo común.

${ }^{50}$ ABC Color, Asunción, 22/04/1979, p. 7.

${ }^{51}$ La ONU, el 15 de diciembre de 1978, había censurado la represión contra la población civil de Nicaragua y la violación de la soberanía de Costa Rica por parte de la aviación militar de Nicaragua. Ver comunicado completo: $<$ http://www.un.org/es/comun/docs/?symbol=A/RES/33/76\&Lang=S>.

${ }^{52}$ ABC Color, Asunción, 23/04/1979, p. 12.
} 


\section{Redes y organizaciones anticomunistas en Paraguay. La XII Conferencia Anual de la Liga Anticomunista Mundial, realizada en Asunción en 1979}

del más absoluto libre mercado: "Las naciones libres deben apoyar en forma activa el progreso económico y social de los países en vías de desarrollo, abandonando su comercio proteccionista, quitando las barreras tarifarias"53. Este razonamiento supone que la libertad económica arroja estabilidad política y con ello disipa la "infiltración y subversión económica". De ahí que el petróleo, en plena crisis mundial, haya sido otro punto nodal del documento final, con el llamado a "las naciones no comunistas a poder acordar abastecimiento y un precio".

\section{Conclusiones}

A mediados de los años 1970, como se ha dicho a lo largo de este trabajo, en un contexto consignado por el inicio de una nueva etapa de la Guerra Fría y de la LAN, Paraguay adoptó una nueva agenda geopolítica. Puede incluso afirmarse que las derechas autoritarias del Cono Sur sufrieron un redireccionamiento estratégico en esa época, que a muchas les valió nuevos apoyos políticos y económicos. En el marco de la alianza entablada con los países de la LAM, el stronismo recreó su identidad anticomunista cuando EE.UU. apelaba a otros horizontes de sentido de la Guerra Fría. Con ello, el régimen reforzaba sus mecanismos autoritarios — tanto en el orden político con la enmienda reeleccionista como en el plano represivo- frente a diversos actores que comenzaban a desenmascararlo.

El stronismo configuró su identidad de derecha en una apelación constante al comunismo, aun cuando la interpelación de esa ideología no fue lineal ni tuvo los mismos frentes de lucha. En efecto, la convergencia de interés y cooperación con la política exterior norteamericana no implicó una total subordinación; la identidad anticomunista se fue constituyendo y fue mutando a partir de los intercambios con otras derechas que pregonaban la misma lucha. Para ello se crearon instituciones y se fomentaron encuentros y lecturas comunes, y se pusieron en práctica planes sistemáticos de persecución política, pero también de adoctrinamiento ideológico. Parte de esa nueva identidad anticomunista de esta coyuntura quedaba sintetizada en la editorial de la LAM publicada en el diario $A B C$ Color, titulada "Sepamos ser anticomunistas". En ella se declaraba: "Al comunismo no se lo combate solamente en los congresos, desde las grandes tribunas ni tampoco solamente en las oscuras oficinas policiales. Luchar contra el comunismo no requiere decir torturas ni matar comunistas. Todo lo contrario. Significa estudiar las causas que le dan origen y vuelo a esa ideología ... las injusticias sociales y económicas contribuyen para que esa ideología gane adeptos" 54 .

Con todo ello se reelaboraba una identidad anticomunista acorde a la época en que, en parte, se asociaba el bienestar con la libertad democrática y anticomunista, es decir, como forma de saldar el autoritarismo de las "derechas" y de las "izquierdas"; se planteaba una suerte de reposición de la vieja hipótesis de la Alianza para el Progreso, pero reemplazando el intervencionismo estatal y el financiamiento

\footnotetext{
${ }^{53}$ ABC Color, Asunción, 27/04/1979, p. 13.

${ }^{54}$ ABC Color, Asunción, 22/04/1979, p. 10.
} 


\section{Lorena Soler}

externo por la mera libertad de mercado. Parte de esta nueva dirección del mundo se reafirmó tras la crisis del socialismo real y las transiciones a la democracia vividas en América Latina, con la excepción de Chile y Argentina, que atravesaron experiencias previas. Son los primeros vestigios de un proyecto neoconservador en marcha.

Al mismo tiempo, la LAM fue un espacio que le permitió al stronismo proyectarse internacionalmente y recostarse en ella cuando se pusieron en crisis sus relaciones con la EE.UU. y cuando dejaba de gozar de los más altos niveles de popularidad y legitimidad social. Como hemos intentado desarrollar, "las redes trasnacionales contrarrevolucionarias generaron espacios de contacto y cooperación donde confluían aparatos estatales, vínculos personales entre élites domésticas y regionales, organizaciones de la sociedad civil, grupos económicos y redes locales de base. Estas redes trasnacionales estaban sustentadas en valores y discursos comunes, así como también en un intercambio fluido de información, know how y recursos" 55 .

Con el cambio del contexto internacional, muchos responsables de la LAM se implicaron en los comités de campaña de Ronald Reagan. Bajo los Gobiernos de éste y de Bush se creó el Consejo para la Libertad Mundial de EE. UU. (World Freedom Council), presidido por el general John K. Singlaub, presidente a su vez de la LAM. En 1985, Ku Cheng-kang, presidente honorario de la Liga Anticomunista Mundial, visitó Paraguay para participar en la Segunda Sesión Plenaria de la Alianza Democrática Latinoamericana, uno de los trece capítulos regionales de dicha liga. Tras la caída del bloque soviético y el durante la Administración de William J. Clinton, la Liga Anticomunista Mundial fue reemplazada por Liga Mundial por la Libertad y la Democracia. Con ella se abre un nuevo capítulo para el estudio de las nuevas redes de las derechas.

\section{Bibliografía}

Andrew Nickson. La Guerra Fría y el Paraguay. Asunción, El Lector, 2014.

Ariel Armony. "Transnacionalización de la guerra sucia: Argentina en Centroamérica", en Daniela Spenser (coordinadora), Los espejos de la Guerra Fría: México, América Central y el Caribe. México D. F., Centro de Investigaciones y Estudios Superiores en Antropología Social, 2004.

Benedetta Calandra y Marina Franco (editores). La guerra fría cultural en América Latina. Buenos Aires, Biblos, 2012.

\footnotetext{
${ }^{55}$ Ariel Armony. “Transnacionalización de la guerra sucia...”, Op. Cit., pp. 347 y 348.
} 
Redes y organizaciones anticomunistas en Paraguay. La XII Conferencia
Anual de la Liga Anticomunista Mundial, realizada en Asunción en 1979

Dionisio Borda y Fernando Masi (editores). Estado y economía en Paraguay. 18702010. Asunción, CADEP, 2010.

Ernesto Bohoslavsky. "Organizaciones y prácticas anticomunistas en Argentina y Brasil (1945-1966)”. Estudos Ibero-Americanos, Vol. XLII, N 1, enero-abril. Porto Alegre, PUCRS, 2016, pp.34-52.

Ernesto Bohoslavsky. "Treinta flores de ciruelo y treinta flores de mburucuyá. Los vínculos de la World Anticommunist League con América Latina durante la guerra fría”, en Samantha Quadrat y Ana Mauad (eds.) Memória e História: questões para o tempo presente, Letra e Voz, Río de Janeiro, en prensa.

Fabricio Antonio Fonseca Fernández. "En búsqueda de la visibilidad: la cooperación internacional de Taiwán", en Francisco Javier Haro Navejas y Kenia María Ramírez Meda, (coordinadores), Cooperación internacional para el desarrollo y su futuro incierto: teoría, actores, cambios y límites. Mexicali, Universidad Autónoma de Baja California, 2017, pp. 225-309.

Frank Mora y Jerry Cooney. El Paraguay y los Estados Unidos. Asunción, Intercontinental, 2009.

Friedrich Katz, "La Guerra Fría en América Latina", en Daniela Spenser (coordinadora), Los espejos de la Guerra Fría: México, América Central y el Caribe. México D. F., Centro de Investigaciones y Estudios Superiores en Antropología Social, 2004, pp.11-31.

Julieta Rostica. "La confederación anticomunista latinoamericana y las Fuerzas Armadas. Guatemala y los años setenta", ponencia presentada en Segundo Coloquio Pensar las derechas en América Latina en el siglo XX, Universidad Nacional de General Sarmiento, Los polvorines, Buenos Aires, 2016.

Luis Hernán Ávila. "Las guerrillas blancas: anticomunismo transnacional e imaginarios de derechas en Argentina y México, 1954-1972". Quinto Sol, Vol. XIX, N 1, enero-abril. Santa Rosa, Universidad Nacional de La Pampa, 2015, pp. 1-26.

María Dolores Béjar. Historia del Siglo XX. Buenos Aires, Siglo XXI, 2011.

Raúl Burgos Pinto. "Aproximaciones a la construcción del anticomunismo en la derecha política conservadora en Chile, 1941-1948". Estudos Ibero-Americanos, Vol. XL, N 2, jul.-dez. Porto Alegre, PUCRS, 2014, pp.258-276.

Ricardo Yegros Scavone y Liliana Brezzo. Historia de las relaciones internacionales del Paraguay. Asunción, El Lector, 2010. 


\section{Lorena Soler}

Rodrigo Patto Sá Motta. "O anticomunismo nas pesquisas de opinião: Brasil, 19551964". Nuevo Mundo, Mundo Nuevo [en línea], Colloques. 2014, p.1. Disponible en: $<$ https://nuevomundo.revues.org/68817>. [Consulta: 25/04/2017].

Soler, Lorena. La larga invención del golpe. El stronismo y el orden político paraguayo. Buenos Aires, Imago Mundi, 2012.

Thierry Meyssan y María Rosa Borrás. "La liga anticomunista mundial, una internacional del crimen". Mientras Tanto, N 93. Barcelona, Icaria Editorial, 2004, pp.133-139.

\section{Documentos}

Diario Hoy, abril y mayo de 1979.

Diario $A B C$ Color, abril y mayo de 1979.

Documentos de Cancillería y del Ministerio de Relaciones Exteriores, 1979.

Informe de la Comisión de Verdad y Justicia, Tomo I y Tomo VII, Asunción, 2008.

Ley de Defensa de la Democracia (Ley No 294, 17/10/1955).

Memorando organizativo, 1979.

Recibido: 04/10/2018

Evaluado: 01/11/2018

Versión Final: 17/12/2018 